\title{
Pulmonary haemodynamics and mortality in chronic hypersensitivity pneumonitis
}

\author{
To the Editor:
}

Chronic hypersensitivity pneumonitis (CHP) is a common interstitial lung disease (ILD) frequently associated with lung fibrosis [1]. Among patients with CHP, the degree of pulmonary function impairment and the extent of fibrosis are known predictors of mortality [2, 3]. In other forms of ILD, such as idiopathic pulmonary fibrosis (IPF) and sarcoidosis, abnormal pulmonary haemodynamics measured during resting supine right heart catheterisation (RHC) are additionally associated with poor prognosis [4-7]. In CHP, however, the prognostic value of RHC is unknown.

We recently found that pulmonary hypertension $(\mathrm{PH})$, defined by a mean pulmonary arterial pressure $(\mathrm{mPAP}) \geqslant 25 \mathrm{mmHg}$ at RHC, is a prevalent feature of CHP [8]. In the current report, we extend our analysis evaluating the association between pulmonary haemodynamics and mortality in this population.

This was an observational study, assessing mortality rates in a previously published cohort of CHP patients that underwent a standardised $\mathrm{PH}$ assessment protocol, including RHC [8]. As previously reported [8], data were collected between August 2011 and February 2013 at the ILD Outpatient Clinic of the Federal University of São Paulo, Brazil. 1023 consecutive outpatients with ILD were evaluated during the study period to identify those with CHP without relevant comorbidities or post-capillary PH $(n=47)$. Mortality rates were assessed up until June 2016. Data are presented as mean \pm SD or median (interquartile range) for normally and non-normally distributed variables, respectively, based on the Shapiro-Wilk statistic. Comparisons between survivors and nonsurvivors were made using the t-test for normally or Mann-Whitney test for non-normally distributed variables. Categorical variables were compared using Chi-squared and Fisher exact tests. Receiver operating characteristics (ROC) curves were used to obtain the best haemodynamic cut-offs for prognostication. Cox proportional hazards and Kaplan-Meier cumulative survival analyses were performed following standard procedures. Correlation analysis between forced vital capacity (FVC) and arterial oxygen saturation $\left(\mathrm{SaO}_{2}\right)$ versus pulmonary vascular resistance (PVR) and pulmonary vascular compliance (PVC) were performed to examine the association between ILD severity and pulmonary vascular dysfunction. $\mathrm{p}<0.05$ was considered significant.

The study sample $(\mathrm{n}=47)$ included 25 non-PH and 22 pre-capillary PH patients [8], with 12 subjects having severe pre-capillary $\mathrm{PH}$, defined by $\mathrm{mPAP}>35 \mathrm{mmHg}$ or $\mathrm{mPAP} \geqslant 25 \mathrm{mmHg}$ associated with a cardiac index $<2.5 \mathrm{~L} \cdot \mathrm{min}^{-1} \cdot \mathrm{m}^{-2}$ [9]. Median follow-up was $40(29-46)$ months. Overall mortality was $45 \%$ (21 out of 47 patients); 1-year, 2-year and 3-year mortality rates were 13\% (six out of 47 patients), $21 \%$ (10 out of 47 patients) and 36\% (17 out of 47 patients), respectively. Among severe PH patients, 1-year, 2 -year and 3-year mortality rates were $33 \%$ (four out of 12 ), $42 \%$ (five out of 12 ) and $58 \%$ (seven out of 12), respectively. The mean age was $57 \pm 13$ years for nonsurvivors and $64 \pm 9$ years for survivors $(\mathrm{p}=0.06)$, without sex differences between these groups (76 versus $77 \%$ females, $\mathrm{p}=0.61$ ). $\mathrm{FVC}$ and $\mathrm{SaO}_{2}$ for nonsurvivors versus survivors were $44 \pm 4$ versus $72 \pm 18 \%$ predicted $(\mathrm{p}<0.01)$ and 89 (84-94) versus 95 (93$96) \%(\mathrm{p}<0.01)$, respectively. Time from CHP diagnosis was 10 (1-25) months for nonsurvivors and 36 (982) months for survivors $(\mathrm{p}=0.03)$.

At resting RHC, nonsurvivors had elevated mPAP, elevated transpulmonary gradient (TPG), elevated diastolic pulmonary gradient (DPG), elevated PVR and decreased PVC compared to survivors (mPAP $28 \pm 7$ versus $24 \pm 5 \mathrm{mmHg}, \mathrm{p}=0.05$; TPG $19 \pm 7$ versus $14 \pm 4 \mathrm{mmHg}, \mathrm{p}=0.01$; DPG $12 \pm 5$ versus $8 \pm 4 \mathrm{mmHg}$, $\mathrm{p}=0.02 ;$ PVR $4.1 \pm 1.8$ versus $2.8 \pm 0.9$ Wood units (WU), $\mathrm{p}=0.01$; and PVC 3.0 (1.8-4.0) versus

@ERSpublications

Indices of pulmonary vascular dysfunction are associated with mortality in chronic hypersensitivity pneumonitis http://ow.ly/1nwG30jwTSm

Cite this article as: Oliveira RKF, Ota-Arakaki JS, Gomes PS, et al. Pulmonary haemodynamics and mortality in chronic hypersensitivity pneumonitis. Eur Respir J 2018; 51: 1800430 [https://doi.org/10.1183/ 13993003.00430-2018]. 
$\left.4.2(2.9-4.8) \mathrm{mL} \cdot \mathrm{mmHg}^{-1}, \mathrm{p}=0.07\right)$. There were no differences in cardiac index between survivors and nonsurvivors $\left(2.7 \pm 0.4\right.$ versus $\left.2.7 \pm 0.5 \mathrm{~L} \cdot \mathrm{min}^{-1} \cdot \mathrm{m}^{-2}, \mathrm{p}=0.89\right)$.

By ROC curve analysis, the optimal cut-off point to separate nonsurvivors from survivors was $24 \mathrm{mmHg}$ for mPAP (area under the curve (AUC) 0.66, $\mathrm{p}=0.07$ ), $15 \mathrm{mmHg}$ for TPG (AUC 0.71, p=0.01), $10 \mathrm{mmHg}$ for DPG (AUC 0.69, $\mathrm{p}=0.02$ ), $3.3 \mathrm{WU}$ for PVR (AUC 0.71, $\mathrm{p}=0.01$ ) and $3.6 \mathrm{~mL} \cdot \mathrm{mmHg}^{-1}$ for PVC (AUC 0.69, $\mathrm{p}=0.03$ ). After adjusting for age, sex and time from CHP diagnosis, a TPG $\geqslant 15 \mathrm{mmHg}$ (HR 4.72, 95\% CI 1.47-15.16, $\mathrm{p}=0.01$ ), a PVR $\geqslant 3.3 \mathrm{WU}$ (HR 3.23, 95\% CI 1.29-8.09, $\mathrm{p}=0.01$ ) and a PVC $\leqslant 3.6 \mathrm{~mL} \cdot \mathrm{mmHg}^{-1}$ (HR 3.52, 95\% CI 1.41-8.80, p=0.01) remained predictors of mortality. By KaplanMeier survival curve analysis, the aforementioned PVR and PVC thresholds dichotomised nonsurvivors from survivors starting at 6 months following RHC (figure 1). The coefficient of determination $\left(\mathrm{R}^{2}\right)$ between FVC (\% predicted) and PVR, and between FVC (\% predicted) and PVC was $0.32(\mathrm{p}<0.01)$ and $0.15(\mathrm{p}<0.01)$, respectively. The coefficient of determination between $\mathrm{SaO}_{2}$ and PVR, and $\mathrm{SaO}_{2}$ and PVC was $0.47(\mathrm{p}<0.01)$ and $0.31(\mathrm{p}<0.01)$, respectively.

In summary, we found that abnormal pulmonary haemodynamics at RHC are associated with mortality in patients with CHP. These findings suggest that pulmonary vascular dysfunction, characterised by elevated PVR and decreased PVC, has negative long-term prognostic implications in CHP.

In patients with sarcoidosis and IPF, PVR $>3 \mathrm{WU}$ [7] and $>6.23 \mathrm{WU}$ [6], respectively, have been associated with worse survival. In addition, minor elevations of mPAP were also found to predict patients' outcomes in IPF $[4,5]$. In the current study, mPAP per se was not a strong predictor of mortality; however, patients with PVR $\geqslant 3.3 \mathrm{WU}$ encountered a more than three-fold increased mortality rate compared with patients with PVR $<3.3 \mathrm{WU}$, despite a similar cardiac index. These observations might be indicative of a yet preserved relationship between the right ventricle (RV) contractility and the afterload, before pulmonary pressures significantly increase and/or the RV becomes dysfunctional [10], as is the case for early stages of pulmonary vascular disease [11].

Along these lines, the optimal PVC cut-off value of $3.6 \mathrm{~mL} \cdot \mathrm{mmHg}^{-1}$ to separate nonsurvivors from survivors was much higher than that previously reported in pulmonary arterial hypertension (PAH) $\left[12,13\right.$. MAнAPATra et al. [12] and CAMPo et al. [13] identified that PVC values of $0.83 \mathrm{~mL} \cdot \mathrm{mmHg}^{-1}$ and $1.25 \mathrm{~mL} \cdot \mathrm{mmHg}^{-1}$ were associated with mortality in patients with idiopathic $\mathrm{PAH}$ and scleroderma-related $\mathrm{PAH}$, respectively. Therefore, our PVC findings probably reflect early pulmonary vascular stiffness $[14,15]$ and ultimately suggest that PVC is clinically relevant to the pathophysiology of ILD.

Taken together, our data add to the framework of understanding the prognostic role of pulmonary vascular insufficiency in ILD, indicating that a mildly increased RV afterload impacts patient's clinical outcome in CHP. Our findings, therefore, should be helpful when risk stratifying patients with CHP and determining the optimal therapeutic strategy, including referral or prioritisation for lung transplantation.

Interestingly, the haemodynamic measurements predicting mortality in the current study were not entirely justified by the severity of the parenchymal lung disease, given the weak/moderate coefficient of determination between FVC and PVR/PVC. In addition, $\mathrm{SaO}_{2}$ explained $<50 \%$ of the observed pulmonary vascular dysfunction. Therefore, the elevated PVR and decreased PVC of CHP nonsurvivors are likely a consequence of multiple pathophysiological mechanisms converging on pulmonary vascular remodelling, such as chronic inflammation, distortion of the lung microcirculation (probably enhanced by the CHP
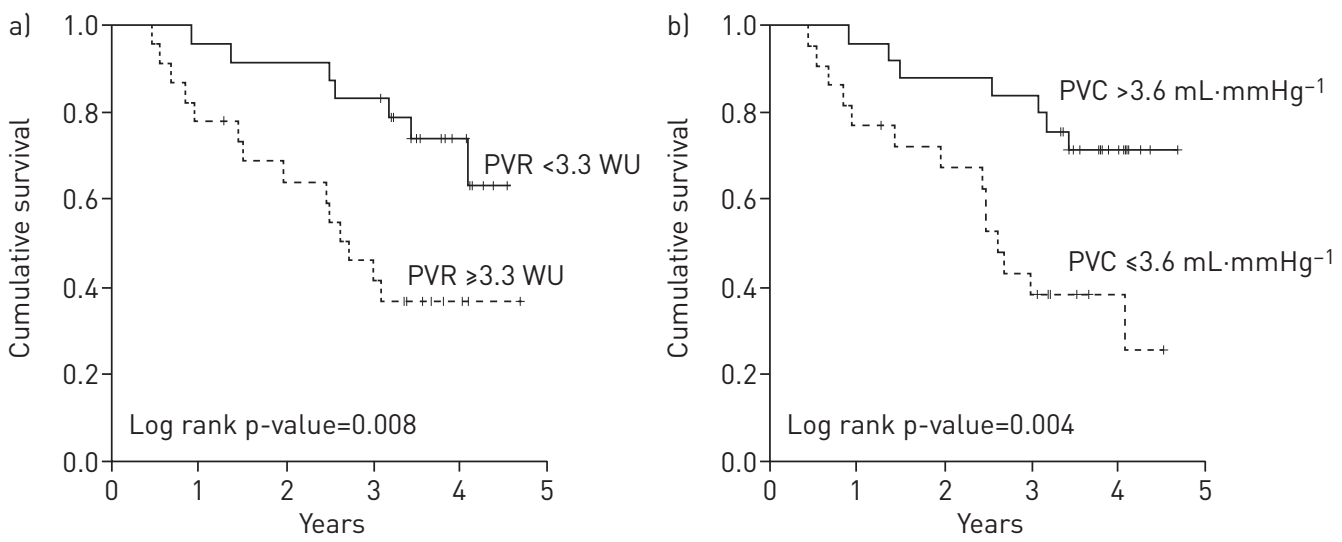

FIGURE 1 Kaplan-Meier survival curves for a) pulmonary vascular resistance (PVR) and b) pulmonary vascular compliance (PVC) in patients with chronic hypersensitivity pneumonitis. 
bronchiolocentric pattern), hypoxic vasoconstriction, and endothelial and vascular smooth muscle cell dysfunction.

The current study is limited by the small sample size and relatively low number of events. However, to the best of our knowledge, this is the largest cohort of patients with CHP reported, to date, prospectively evaluated with invasive haemodynamics and with long-term follow-up, and as such, the current data provides an important insight into the prognostic role of pulmonary vascular dysfunction in this population.

In conclusion, indices of pulmonary vascular dysfunction are associated with mortality in CHP, providing therefore valuable prognostic information. In addition to the identification of decreased FVC and $\mathrm{SaO}_{2}$, which were also associated with mortality, the identification of an elevated PVR and decreased PVC should be helpful when accessing prognosis in CHP and determining prioritisation or referral for lung transplantation.

Rudolf K.F. Oliveira $\oplus^{1}$, Jaquelina S. Ota-Arakaki ${ }^{1}$, Paula S. Gomes ${ }^{1}$, Andrea Gimenez ${ }^{1}$, Carolina M.S. Messina ${ }^{1}$, Roberta P. Ramos ${ }^{1}$, Eloara V.M. Ferreira ${ }^{1}$, David M. Systrom ${ }^{2}$ and Carlos A.C. Pereira ${ }^{1}$

${ }^{1}$ Division of Respiratory Diseases, Dept of Medicine, Federal University of São Paulo (Unifesp), São Paulo, Brazil.

${ }^{2}$ Division of Pulmonary and Critical Care Medicine, Dept of Medicine, Brigham and Women's Hospital and Harvard Medical School, Boston, MA, USA.

Correspondence: Rudolf K.F. Oliveira, Division of Respiratory Diseases, Dept of Medicine, Federal University of São Paulo (Unifesp), Rua Botucatu, 740 - $3^{\circ}$ andar, CEP 04039-002, São Paulo, SP, Brazil. E-mail: rudolf.oliveira@outlook. com

Received: Nov 292017 | Accepted after revision: March 252018

Conflict of interest: None declared.

Support statement: Pulmonary Vascular Disease Service, Division of Respiratory Diseases, Department of Medicine. Federal University of São Paulo (Unifesp), São Paulo, SP, Brazil. Funding information for this article has been deposited with the Crossref Funder Registry.

\section{References}

1 Pereira CA, Gimenez A, Kuranishi L, et al. Chronic hypersensitivity pneumonitis. J Asthma Allergy 2016; 9: $171-181$.

2 Walsh SLF, Sverzellati N, Devaraj A, et al. Chronic hypersensitivity pneumonitis: high resolution computed tomography patterns and pulmonary function indices as prognostic determinants. Eur Radiol 2012; 22: 1672-1679.

3 Mooney JJ, Elicker BM, Urbania TH, et al. Radiographic fibrosis score predicts survival in hypersensitivity pneumonitis. Chest 2013; 144: 586-592.

4 Hamada K, Nagai S, Tanaka S, et al. Significance of pulmonary arterial pressure and diffusion capacity of the lung as prognosticator in patients with idiopathic pulmonary fibrosis. Chest 2007; 131: 650-656.

5 Kimura M, Taniguchi $\mathrm{H}$, Kondoh $\mathrm{Y}$, et al. Pulmonary hypertension as a prognostic indicator at the initial evaluation in idiopathic pulmonary fibrosis. Respiration 2013; 85: 456-463.

6 Corte TJ, Wort SJ, Gatzoulis MA, et al. Pulmonary vascular resistance predicts early mortality in patients with diffuse fibrotic lung disease and suspected pulmonary hypertension. Thorax 2009; 64: 883-888.

7 Baughman RP, Engel PJ, Taylor L, et al. Survival in sarcoidosis-associated pulmonary hypertension: the importance of hemodynamic evaluation. Chest 2010; 138: 1078-1085.

8 Oliveira RKF, Pereira CAC, Ramos RP, et al. A haemodynamic study of pulmonary hypertension in chronic hypersensitivity pneumonitis. Eur Respir J 2014; 44: 415-424.

9 Galiè N, Humbert M, Vachiery J-L, et al. 2015 ESC/ERS Guidelines for the diagnosis and treatment of pulmonary hypertension: The Joint Task Force for the Diagnosis and Treatment of Pulmonary Hypertension of the European Society of Cardiology (ESC) and the European Respiratory Society (ERS): Endorsed by: Association for European Paediatric and Congenital Cardiology (AEPC), International Society for Heart and Lung Transplantation (ISHLT). Eur Respir J 2015; 46: 903-975.

10 Panagiotou M, Church AC, Johnson MK, et al. Pulmonary vascular and cardiac impairment in interstitial lung disease. Eur Respir Rev 2017; 26: 160053.

11 Vonk NA, Westerhof BE, Westerhof $\mathrm{N}$. The relationship between the right ventricle and its load in pulmonary hypertension. J Am Coll Cardiol 2017; 69: 236-243.

12 Mahapatra S, Nishimura RA, Sorajja P, et al. Relationship of pulmonary arterial capacitance and mortality in idiopathic pulmonary arterial hypertension. J Am Coll Cardiol 2006; 47: 799-803.

13 Campo A, Mathai SC, Le Pavec J, et al. Hemodynamic predictors of survival in scleroderma-related pulmonary arterial hypertension. Am J Respir Crit Care Med 2010; 182: 252-260.

14 Sanz J, Kariisa M, Dellegrottaglie S, et al. Evaluation of pulmonary artery stiffness in pulmonary hypertension with cardiac magnetic resonance. JACC Cardiovasc Imaging 2009; 2: 286-295.

15 Oliveira RKF, Waxman AB, Agarwal $M$, et al. Pulmonary haemodynamics during recovery from maximum incremental cycling exercise. Eur Respir J 2016; 48: 158-167. 